\title{
ANÁLISE DO EXTRATIVISMO E DAS PRÁTICAS AGROPECUÁRIAS EM COMUNIDADES QUILOMBOLAS DA ILHA DO CAJUAL, ALCÂNTARA - MA
}

\author{
Ana Raissa de Oliveira Gomes ${ }^{(a)}$, Elaine Cunha Vieira ${ }^{(b)}$, Marcelino Silva Farias Filho ${ }^{(c)}$ \\ (a) Acadêmica de Geografia, Universidade Federal do Maranhão, raissagomes90@gmail.com \\ (b) Acadêmica de Geografia, Universidade Federal do Maranhão, elai.cv@ @otmail.com \\ (c) Professor Doutor do Departamento de Geociências, Universidade Federal do Maranhão, marcelinofarias@ ufma.br
}

\section{Eixo: Solos e Paisagem}

\begin{abstract}
Resumo
A maioria das práticas de manejo acarreta modificações que resultam em perdas de sedimentos e na degradação física e empobrecimento químico dos solos. Em comunidades rurais do Maranhão, as práticas agropecuárias ocasionam danos ambientais, especialmente aos solos. Este trabalho analisou a importância e consequências do extrativismo e agropecuária nos solos da ilha do Cajual, em Alcântara - Maranhão a partir do método indutivo e percepção desenvolvida em atividade de campo da disciplina de Pedologia do Curso de Geografia da Universidade Federal do Maranhão. A cobertura vegetal da ilha tem passado por modificações devido às práticas agropecuárias e ao sistema tradicional de preparo do solo assentado no corte e queima da vegetação. Os solos, naturalmente distróficos, têm sido degradados fisicamente e empobrecido quimicamente, o que resulta em baixos níveis de produtividade das culturas e em problemas sociais.
\end{abstract}

Palavras chave: Extrativismo. Práticas Agropecuárias. Ilha do Cajual - Alcântara.

\section{Introdução}

Desde o período Neolítico, o homem vem sendo o principal agente transformador do ambiente. Ele aprendeu a cultivar plantas e a produção da sua alimentação, consequentemente, passou a envolver o domínio de técnicas sobre o solo (MAZOYER; ROUDART, 2010). De certo, a evolução do homem não eximiu o meio ambiente da transformação e, nesse processo, a vida vegetal foi a que mais sofreu alteração com o desmatamento em função das atividades agropecuárias que, na época eram de manutenção, mas que, atualmente, tomaram outro rumo tendo em vista que as relações sociais já não são mais as mesmas.

Na ilha do Cajual, localizada em Alcântara, estado do Maranhão, a atuação antrópica por meio da agropecuária, apresenta impactos negativos associados à supressão da vegetação nativa e desequilíbrios ecológicos em decorrência do modelo de uso da terra adotado (agricultura itinerante de corte e queima e pecuária extensiva), do aumento do número de animais de grande porte (bovino) e médio porte (suíno) no território insular que possuem elevado potencial de degradação dos solos e do restrito conhecimento por parte dos habitantes da ilha em relação à estrutura, atributos e técnicas de conservação dos solos. Entre os efeitos mais perceptíveis, em curto prazo, estão a supressão da cobertura vegetação e a simplificação da 
sua estrutura pelo domínio de algumas espécies, como a Orbygnia speciosa, bem como as perdas de solos visíveis nas áreas cultivos e de pastoreio.

Este trabalho analisou, qualitativamente, as mudanças ocorridas na cobertura vegetal e o empobrecimento dos solos devido às práticas mencionadas levando em consideração as comunidades quilombolas que residem na Ilha do Cajual, Alcântara - MA.

\section{Materiais e Métodos}

O presente trabalho foi desenvolvido mediante o uso do método indutivo, levando-se em consideração a observação e análise de fatos partindo de dados particulares para o geral (MARCONI; LAKATOS, 2003). Como procedimentos metodológicos, foram adotadas a revisão de literatura e as atividades de campo realizadas em dezembro de 2015 e agosto de 2016, parte das atividades didáticas da disciplina de Pedologia ministrada no âmbito do curso de Geografia da Universidade Federal do Maranhão com realização de registros fotográficos e observações in situ. Dentro das atividades de campo observou-se o ambiente em uma caminhada de $12 \mathrm{~km}$ pelo interior da Ilha do Cajual com início no Porto do Cujupe, situado em Alcântara com as coordenadas $2^{\circ} 28^{\prime} 53^{\prime \prime} \mathrm{S}$ e $44^{\circ} 30^{\prime} 50^{\prime \prime} \mathrm{W}$, que integra o sistema marítimo de transporte de passageiros (ferry boat) juntamente com o Porto da Ponta da Espera finalizando-se no litoral, que se localiza a oeste da Ilha do Maranhão, entre as coordenadas $2^{\circ} 32^{\prime} 6.45^{\prime \prime S}$ e $44^{\circ} 21^{\prime} 23.36^{\prime \prime} \mathrm{W}$.

\section{Resultados e Discussões}

A ilha do Cajual, situada no município de Alcântara na porção norte do estado do Maranhão, está localizada entre as coordenadas geográficas $44^{\circ} 31^{\prime} 07,54^{\prime \prime} \mathrm{O}$ e $02^{\circ} 25^{\prime} 36^{\prime \prime} \mathrm{S}$ e $44^{\circ} 26^{\prime} 47^{\prime \prime O}$, e 2³2’22,29”S. Ambientalmente, a ilha está inserida no complexo estuarino do Golfão Maranhense (PEREIRA et al., 2010), caracterizada por depósitos sedimentares das formações Itapecuru, Grupo Barreiras e Aluviões fluviomarinhos. A referida ilha é conhecida, inclusive internacionalmente, pelos sítios paleontológicos e fósseis já catalogados em diversos locais. Segundo Moura (2004), a Formação Itapecuru é do Cretáceo Superior, composta por arenitos finos argilosos ou muito argilosos ricos em argila do grupo das caulinitas. Esta formação, também denominada de fossilífera contribui para remanescentes fósseis encontrados na ilha, considerada um sítio arqueológico. A Formação Barreiras, de acordo com Pereira et al. (2011), aflora, principalmente na Ilha do Maranhão, nas falésias, colinas, encostas e topos dos tabuleiros e podem ser observados na ilha juntos aos tabuleiros que apresentam suas bordas inclinadas suscetíveis à erosão marinha . Os Aluviões fluviomarinhos, situados na porção centro-norte da Ilha do Cajual, compreendem uma formação geológica recente cuja origem tem relação com rupturas e alargamentos dos vales da antiga 
rede hidrográfica da região ocorridas no Quaternário antigo, sendo formada por areia fina e silte (MOURA, 2004).

O relevo ondulado condiciona processos erosivos em entressulcos que são prejudiciais à fertilidade dos solos, pois carreiam a matéria orgânica e as bases solúveis para o mangue. As colinas da região central da ilha, além de servirem como divisor das águas superficiais, também influenciam o clima local, pois bloqueiam parte da umidade e a porção mais a leste da ilha recebe mais precipitação pluviométrica, o que permite que o relevo seja intensamente modelado e as colinas, rebaixadas. Desse modo, os solos são mais pobres, marcados pela presença de areias quartzosas que podem ocasionar a formação de crostas endurecidas na superfície (cimentação) e que dão origem às manchas de Latossolos Amarelos ou a Neossolos Quartzarênicos, ambos distróficos. Esses solos possuem como cobertura vegetal atualmente, vegetação secundária dominada por babaçu (Orbigynea speciosa), fato que denota a degradação destes por sucessivos usos agrícolas no sistema de corte e queima da vegetação (roça).

De acordo com Santos et al. (2012), os solos que predominam na Ilha do Cajual são os Plintossolos Vermelho-Amarelos (PV), localizados ao sul ou litoral sul da ilha. No centro da Ilha, os solos são em sua maioria ácidos sendo os mais expressivos os Plintossolos em áreas de sedimentos finos. Em áreas de sedimentos mais grosseiros estão os Latossolos amarelos e Neossolos Quartzarênicos sendo possível encontrar algumas manchas de Gleissolos em regiões mais alagadiças. Segundo Jacomine et al. (1986), Latossolos Amarelos caracterizam-se por baixa fertilidade e grande profundidade. Os Neossolos Quartzarênicos são solos recentes encontrados na porção nordeste do estado do Maranhão e Gleissolos são solos hidromórficos com nível alto de acidez (SANTOS et al., 2013). No norte da ilha predominam os sedimentos inconsolidados de mangue que são caracterizados pela indefinição de horizontes. Na porção oeste da ilha predominam solos relativamente mais férteis, com sedimentos finos compostos de argila com material plíntico em função da saturação hídrica durante o período chuvoso devido à retenção da água nos horizontes A ou B.

A ilha do Cajual é habitada por um número pequeno de comunidades quilombolas que manejam o solo com a agricultura de corte e queima da vegetação (roça), atividade de pequeno porte, que é praticada em áreas mais úmidas. $\mathrm{O}$ material mais fértil é levado para a encosta onde os moradores fazem roça, pois a umidade infiltra no topo e é conduzida pela gravidade no perfil do solo é transportada para o material coluvionar.

A agricultura de corte e queima pode gerar problemas como o desaparecimento de espécies de animais, o empobrecimento do solo e degradação ambiental em função da redução da vegetação nativa (FARIAS FILHO, 2006), especialmente quando há uma intensificação do uso dos solos com a consequente redução 
do tempo de pousio, realidade típica da Ilha do Cajual. Tais atividades têm gerado supressão da vegetação nativa e ocasionado desequilíbrios ecológicos representados pelo predomínio de palmáceas como babaçu (Orbygnia Speciosa), que é favorecida pelo desmatamento e queima da vegetação, em todas as áreas em que a agricultura foi ou é praticada. Em contrapartida, a queima da vegetação proporciona a correção da acidez do solo, o enriquece com nutrientes e reduz a incidência de pragas, doenças e de ervas espontâneas no período de cultivo.

Nos sistemas agrícolas, as famílias têm produção diversificada, mas, em geral, cultivam plantas tolerantes à acidez dos solos e à pobreza química. Dentre os produtos, destacam-se: a mandioca para a produção de farinha e amido, feijão, milho e curcubitáceas (abóbora e maxixe). A abertura de áreas para a inserção dessas culturas destrói a estrutura florestal que poderia ser muito rentável com a prática do extrativismo vegetal (babaçu, murici e bacuri). Entretanto, sendo o principal alimento a farinha e peixe, a comunidade acaba que tendo que desmatar e fazer pequenas roças.

A mandioca é beneficiada para a produção de farinha de puba ou d'água, cujo modo de preparo envolve a fermentação dos tubérculos (ato de "pubar", daí o nome da farinha) para redução do teor de ácido cianídrico em cavidade escavadas nas planícies fluviais para o armazenamento de água. Do processo de decomposição da mandioca resultam a emissão de odores e a contaminação dos solos e mananciais pela manipueira ou tucupi (extrato contendo os ácidos que são expulsos da mandioca no processo de fermentação). Como não há renovação da água para a produção da farinha a sua qualidade acaba sendo comprometida.

A pecuária extensiva (bovinos, suínos e galináceas), extrativismo vegetal e a pesca são também importantes atividades econômicas locais. Segundo Silva (2006, p. 122), a criação de bovinos gera diversos problemas ambientais comprometendo a drenagem e capacidade hídrica do solo proporcionando a compactação e impermeabilização, devido ao pisoteio excessivo do gado. Na porção sudoeste da ilha pode-se perceber solo compactado pelo pisoteio dos animais e por moradores da comunidade, com sinais de remoção de matéria orgânica por processo erosivos em entressulcos.

\section{Considerações Finais}

A ilha de Cajual apresenta, predominantemente, Plintossolos Vermelho-Amarelos, Latossolos Amarelos que são solos com limitadas potencialidades agrícolas, por serem fortemente ácidos, apresentarem baixa fertilidade e drenagem reduzida. Tais características pedológicas reduzem a possibilidade de desenvolvimento agrícola e direciona as famílias ao desenvolvimento de outras atividades, como a pesca, pecuária e o extrativismo. 


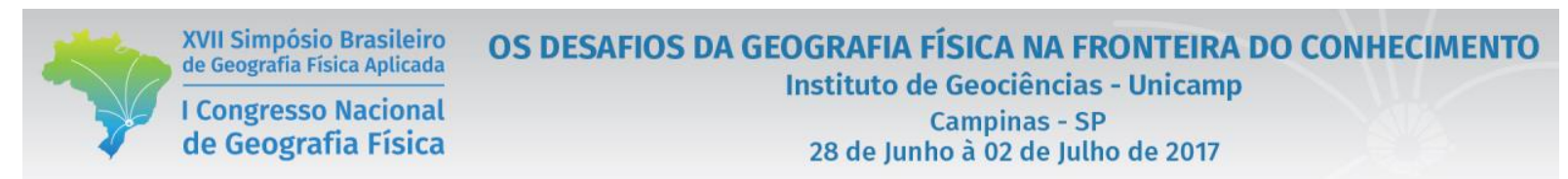

A composição florestal da área é predominantemente de palmáceas, fato que resultou das repetitivas queimadas no ambiente provocando a sua proliferação em toda paisagem. As atividades locais são essencialmente agricultura de automanutenção e pecuária extensiva, que acarretam impactos negativos sobre o ambiente, como a compactação do solo ocasionado pelo pisoteio excessivo das planícies por gado bovino e desmatamento da vegetação nativa em decorrência do sistema de corte e queima. Além disto, a Ilha, considerado um sítio arqueológico, tem perdido registros fósseis.

\section{Bibliografia}

FARIAS FILHO, M. S. Caracterização e Avaliação do Cultivo do Arroz em Sistema de Vazante na Baixada Maranhense. 2006. 128 f. Dissertação (Mestrado em Agroecologia) - Universidade Estadual do Maranhão, São Luís.

JACOMINE, P. K. T. et al. Levantamento exploratório-reconhecimento de solos do Estado do Maranhão. Rio de Janeiro, EMBRAPA-SNLCS/SUDENE. DRN, 1986.

LAKATOS, E. M.; MARCONI, M. A. Metodologia Científica, Editora Atlas S.A., São Paulo SP, 2003.

MARZOYER M.; ROUDART L.; [tradução de Cláudia F. Falluh Balduino Ferreira]. História das agriculturas no mundo: do neolítico à crise contemporânea. - São Paulo: Editora UNESP; Brasília, DF: NEAD, 2010.

MOURA, E. G, de (org.). Agroambientes de transição - Entre o tropico úmido e o semiárido do Brasil Atributos; alterações; uso na produção familiar. UEMA, São Luís, 2004.

PEREIRA, E. D. Avaliação da vulnerabilidade natural à contaminação do solo e do aquífero do Reservatório Batata - São Luís - MA. 2006. 133 f. Tese (Doutorado em Geociências). Universidade Estadual Paulista, Instituto de Geociências e Ciências Exatas, Rio Claro.

PEREIRA, P. R. M.; et al. Principais Unidades de Paisagens da Ilha do Cajual, Alcântara Maranhão. In: XIV Simpósio Brasileiro de Geografia Física Aplicada, 2011, Dourados. Anais do XIV Simpósio Brasileiro de Geografia Física Aplicada. Dourados, Ms: EDUFGD, 2011. V. 1. P. 1-11.

SANTOS, A.C.G.; et al. Análise Geológica, Geomorfológica e Ambiental da Ilha do Cajual em Alcântara MA. In: $9^{\circ}$ Simpósio Nacional de Geomorfologia, 2012, Rio de Janeiro. Anais do $9^{\circ}$ Simpósio Nacional de Geomorfologia. Rio de Janeiro. 2012.

SANTOS, H. G. dos; et al. Sistema Brasileiro de Classificação de Solos. 3 ed. revista e ampliada Brasília, DF: EMBRAPA, 2013.

SILVA, J. B. da, Org; LIMA, L. C., Org; DANTAS, E. W. C. Org.. Panorama da geografia brasileira II. - São Paulo: Annablume, 2006. p. 122. 